\title{
Value of Shear Wave Elastography for differentiating benign and malignant renal lesions
}

\author{
Sinem Aydin', Seyma Yildiz ${ }^{1}$, Ihsan Turkmen', Rasul Sharifov', Omer Uysal², Zuhal Gucin, \\ Abdullah Armagan ${ }^{4}$ Ercan Kocakoc ${ }^{1}$
}

${ }^{1}$ Department of Radiology, ${ }^{2}$ Department of Biostatistics, ${ }^{3}$ Department of Pathology, ${ }^{4}$ Department of Urology, Bezmialem Vakif University, Faculty of Medicine, Istanbul, Turkey

\begin{abstract}
Aims: To investigate the diagnostic accuracy of shear-wave elastography (SWE) for assessing malignant and benign kidney masses. Materials and methods: Forty patients with solid renal masses underwent US elastographic evaluation. SWE values of the lesions and adjacent cortical renal parenchyma and SWER were detected prospectively. Malignant tumors were recorded as group 1 and benign tumors were recorded as group 2. Results: The highest elasticity values were $27.27 \pm 25.66$ $\mathrm{kPa}$ for group 1 and $16.13 \pm 8.89 \mathrm{kPa}$ for group 2 . The mean $\pm \mathrm{SD}$ elasticity values for adjacent renal cortex for groups 1 and 2 were $2.7 \pm 2.08$ and $2.75 \pm 1.35$, respectively. For group 1 , a negative correlation was observed between the age of the patients and SWER value $(\mathrm{p}=0.047, \mathrm{rs}=-0.401)$. There was also a negative correlation between the SWER value and the SWE value of adjacent renal cortex $(\mathrm{p}=0.004, \mathrm{rs}=-0.555)$. Conclusion: $\mathrm{SWE}$ is a noninvasive method that provides quantitative elasticity information on tissues. Overlaps among different types of renal lesions may be due to heterogeneity of the lesions. Larger study groups may clarify the other factors affecting SWE values under both normal and pathological conditions.
\end{abstract}

Keywords: ultrasonography; elastography; renal neoplasm

\section{Introduction}

The increased availability of imaging equipment has increased the detection of renal masses. It is estimated that more than half of patients over the age of 50 years have at least one renal mass $[1,2]$. The most common malignant mass is renal cell carcinoma, which represents about $2 \%$ of adult cancers. Transitional cell carcinoma (TCC), lymphoma, melanoma, and metastases are other types of malignant masses. Benign tumors account for approximately $20 \%$ of all solid renal cortical tumors; angiomyolipoma (AML) and renal oncocytoma are the most common types [3]. Treatment is important for ma-

Received 29.06.2017 Accepted 17.09.2017

Med Ultrason

2018, Vol. 20, No 1, 21-26

Corresponding author: Sinem Aydin, MD

Department of Radiology, Faculty of Medicine, Bezmialem Vakif University

34093, Istanbul, Turkey

Phone: +90-212-4531700, Fax: +90-212-6217580

E-mail: sinem.rad@gmail.com lignant tumors; it is also appropriate for symptomatic AMLs among the benign ones $[4,5]$.

There is a wide range of management options for renal masses, including radiological follow-up, radiofrequency ablation, cryoablation, partial nephrectomy, and radical nephrectomy. About $27 \%$ of small enhancing renal masses are found to be benign at surgery [6]. Thus, the characterization of lesions and staging of renal masses are vital for the management of patients. However, the precise diagnosis of renal masses remains a major problem. Investigators have looked for accurate imaging methods for the pathological subtyping of renal masses [7-9]. Ultrasound (US), as a first-line imaging technique, is important for detecting renal tumors and discriminating between benign and malignant lesions. Dynamic contrast-enhanced computer tomography (CT) and magnetic resonance imaging (MRI) are now commonly used for these. Unfortunately, both imaging techniques have some disadvantages. For example, high doses of radiation are inevitable in dynamic CT scans, although the exact dose varies according to the scanner and size of the 
patient. Patients with cardiac pacemakers, metallic clips that may cause artifacts, and those suffering from claustrophobia may not be appropriate for MRI. The use of CT and MRI contrast agents may be partially or completely restricted in patients with renal insufficiency and solitary kidney, and this may interfere with the noninvasive diagnosis of renal masses in such patients. Contrast-enhanced US serves as a good alternative for patients with renal insufficiency or allergy to iodinated contrast agents in detecting benign and malignant solid renal lesions [10].

Percutaneous core biopsy is a minimally invasive method for establishing a definitive diagnosis for indeterminate lesions, such as infections and lymphoma, and for confirming the origin of metastatic diseases. Renal mass biopsies are often avoided because of possible complications, such as bleeding, perirenal hematoma, hematuria, arteriovenous fistula formation, and pneumothorax [11]. The risk of tumor seeding, especially of TCC, is another concern.

Thus, it is important to identify another noninvasive and reliable method to distinguish between benign and malignant renal lesions. Shear-wave elastography (SWE) is a procedure for assessing tissue stiffness without external compression $[12,13]$. An acoustic radiation force is used to generate low-frequency $(\sim 50 \mathrm{~Hz})$ mechanical (shear) waves that induce tissue displacement. This technique quantitatively calculates stiffness values in regions of interest.

There are many reports on the accuracy of elastography for diagnosing solid lesions of the breast [14], thyroid [15,16], liver [17], prostate [18], rectum [19], and lymph nodes [20]. However, to the best of our knowledge, few studies have evaluated the success of US elastography for increasing the sensitivity of conventional US for discriminating between benign and malignant renal masses [21-25]. In this study, we investigated the diagnostic accuracy of SWE for assessing malignant and benign kidney masses.

\section{Material and method}

\section{Patients and imaging procedures}

The study was designed in a prospective manner and approved by the Ethics Committee of our institution. Each participant gave written and oral consent. From September 2014 to March 2015, 40 patients who were referred to our institution for further evaluation of a renal mass, or had been diagnosed with a renal mass during a surveillance examination (US, CT, or MRI) at our institution underwent US elastographic evaluations. The values obtained through SWE were compared to the histopathologic examination or follow-up results.

The 40 patients consisted of $23(57.5 \%)$ females, the mean age was $50.13 \pm 16.72$ (range 4-85 years) for wom- en and $50.64 \pm 16.06$ (range 12-81 years) for men, and the mean body mass index was $26.69 \pm 3.09 \mathrm{~kg} / \mathrm{m}^{2}$ (range $19.4-30.8 \mathrm{~kg} / \mathrm{m}^{2}$ ).

B-mode imaging and SWE measurements were made using US equipment (Philips iU22; Eindhoven, the Netherlands) and a curved array probe (C5-1 PureWave transducer), performed by a radiology specialist (SA) with 5 years of US and 3 years of SWE experience. The patients avoided eating for 8 hours before the examination. The patients were examined in the supine, right, or left oblique position, as required. Size, internal echo pattern, contour, and shape of lesions were assessed in B-mode imaging. For quantitative evaluations of stiffness by SWE, the patients were requested to stop breathing, rather than taking a deep breath, because the box for the ROI can be placed in tissues only as deep as $7 \mathrm{~cm}$. The ROI size was fixed depending on the properties of the selected equipment. The lesion was targeted in the B-mode image and the box for ROI was placed in the solid and most echogenic parts of the lesion. Care was taken to avoid placing the ROI in cystic parts or calcifications in the lesion. For interpretation of the SWE ratio (SWER), measurements were obtained from adjacent renal cortex. It is obtained by dividing the mean SWE value of the tumor by that of adjacent renal cortex $(\mathrm{SWER}=\mathrm{SWE}$ tumor $/ \mathrm{SWE}$ cortex $)$. The ROI was positioned carefully to avoid partial effects from the renal medulla or pelvis. Elastography values were quantified in kilopascals $(\mathrm{kPa})$. At least three measurements were performed for each lesion to ensure the quality of SWE, and the highest value was used in statistical analyses (fig 1, fig 2).

\section{Statistical analysis}

The SPSS software (ver. 19) was used to analyze the data. Data are presented as means, standard deviations (SD), and percentages. The lesions were explored in two groups according to the lesion size as $<3 \mathrm{~cm}$ or $\geq 3 \mathrm{~cm}$. The independent-sample $t$-test was used for two-group comparisons of homogenic variances. The Mann-Whitney U-test was used to compare quantitative variables of groups 1 and 2 because they showed heterogeneous variance. Categorical variables were evaluated with the $\chi^{2}$ test. The significance level was set at 0.05 .

\section{Results}

Malignant tumors were recorded as group 1 and benign tumors were recorded as group 2. The mean size was $5.23 \pm 3.42 \mathrm{~cm}$ for group 1 and $4.26 \pm 2.56 \mathrm{~cm}$ for group 2. There were no significant differences between tumor sizes of the two groups.

Each patient had one renal lesion. Thus, 40 lesions were assessed by SWE. The lesions were clear cell RCC 


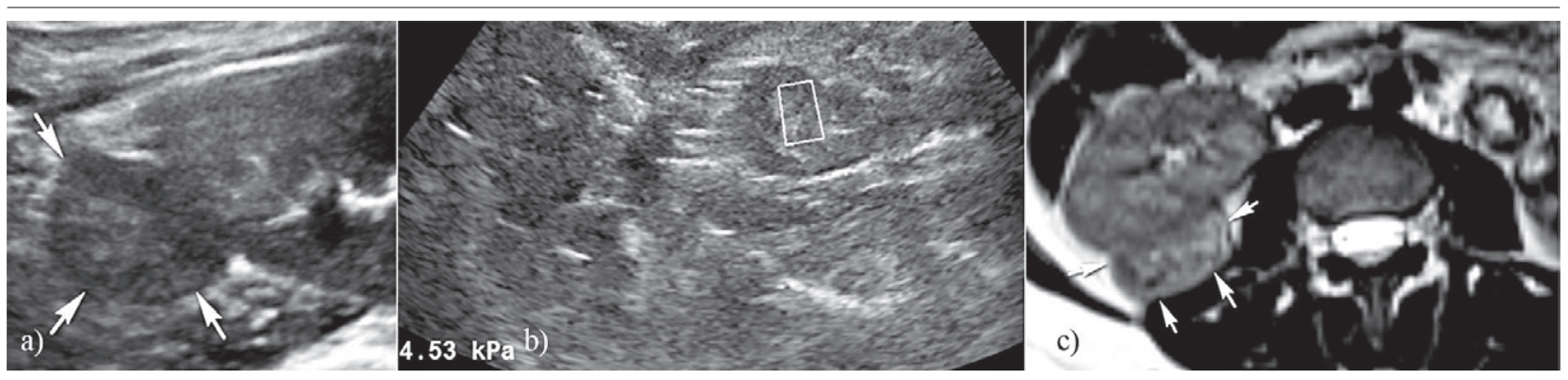

Fig 1. Fat poor angiomyolipoma: a) B-mode US image shows an exophytic hypoechoic heterogeneous mass in the right kidney (arrows); b). Corresponding SWE image shows an elastography value of $4.53 \mathrm{kPa}$ in the most echogenic part of the mass; c) On the T2 weighted MR image the mass is isointense relative to the renal parenchyma without bulk fat. The patient underwent partial nephrectomy and the mass was proven to be fat poor angiomyolipoma.

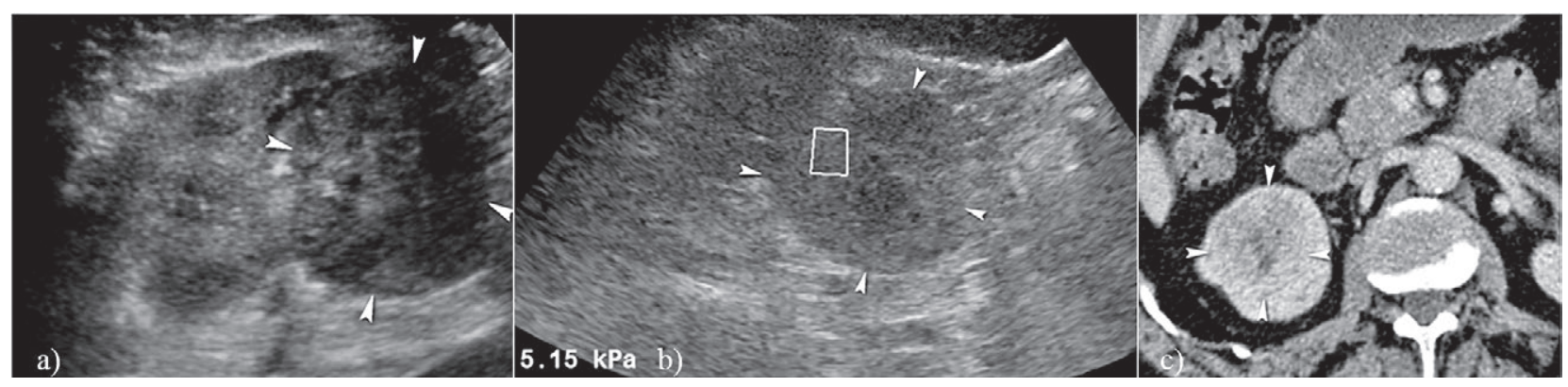

Fig 2. Clear cell RCC: a) B-mode US image shows a heterogenous hypoechoic mass (arrowheads) originating from lower pole of the left kidney; b) The mass has an elasticity value of $5.15 \mathrm{kPa}$; c) Contrast-enhanced axial CT image shows a heterogenous mass enhancing lower than the adjacent renal parenchyma. The patient underwent partial nephrectomy and the mass was proven to be clear cell RCC.

$(\mathrm{n}=17)$, chromophobe RCC $(\mathrm{n}=1)$, TCC $(\mathrm{n}=2)$, liposarcoma $(n=2)$, Wilms tumor $(n=1)$, metastasis $(n=2)$, angiomyolipoma $(\mathrm{n}=9)$, cystic nephroma $(\mathrm{n}=2)$, oncocytoma $(\mathrm{n}=1)$, xanthogranulomatous pyelonephritis $(\mathrm{n}=1)$, abscess $(\mathrm{n}=1)$, and hematoma $(\mathrm{n}=1)$. The RCCs, TCCs, liposarcomas, Wilms tumor, cystic nephromas, oncocytoma, and xanthogranulomatous pyelonephritis were diagnosed histopathologically, by partial or radical ne- phrectomy. The abscess and two metastases were confirmed by sampling, and the hematoma was confirmed by drainage. Eight angiomyolipomas were assessed during follow-up of a previous diagnosis. Only one minimal fat angiomyolipoma, misdiagnosed as RCC by imaging, was confirmed after resection.

The highest elasticity values were $27.27 \pm 25.66 \mathrm{kPa}$ for group 1 and $16.13 \pm 8.89 \mathrm{kPa}$ for group 2 ; the dif-

Table I. SWE and SWER values of assessed renal lesions and histopathologic distribution.

\begin{tabular}{|c|c|c|c|c|c|}
\hline \multirow[t]{2}{*}{ Group } & \multirow[t]{2}{*}{ Diagnosis } & \multirow[t]{2}{*}{$\mathbf{n}$} & \multicolumn{2}{|l|}{ SWE values (kPa) } & \multirow[t]{2}{*}{ SWER } \\
\hline & & & Mass (Mean \pm SD) & Adjacent cortex $($ Mean \pm SD) & \\
\hline \multirow[t]{5}{*}{1} & $\mathrm{RCC}$ & 18 & $31.88 \pm 28.64$ & $2.76 \pm 1.92$ & $42.72 \pm 125.15$ \\
\hline & TCC & 2 & $19.41 \pm 10.04$ & $6.1 \pm 2.3$ & $3.09 \pm 0.47$ \\
\hline & Liposarcoma & 2 & $22.99 \pm 7.97$ & $1.48 \pm 0.45$ & $17.05 \pm 10.49$ \\
\hline & Wilms & 1 & 5.12 & 0.67 & 7.64 \\
\hline & Metastasis & 2 & $8.99 \pm 0.72$ & $1.02 \pm 0.02$ & $8.78 \pm 0.89$ \\
\hline \multirow[t]{6}{*}{2} & Angiomyolipoma & 9 & $17.46 \pm 7.95$ & $2.5 \pm 1.2$ & $9.34 \pm 9.19$ \\
\hline & Cystic nephroma & 2 & $16 \pm 5.74$ & $4.38 \pm 1.3$ & $3.62 \pm 0.24$ \\
\hline & Oncocytoma & 1 & 8.05 & 0.91 & 8.94 \\
\hline & Abscess & 1 & 32.6 & 4.89 & 6.66 \\
\hline & Hematoma & 1 & 3.24 & 1.46 & 2.21 \\
\hline & Xantogranulomatous pyelonephritis & 1 & 8.98 & 2.89 & 3.1 \\
\hline
\end{tabular}

SWE - shear wave elastography, SWER - shear wave elastography ratio of renal lesion to adjacent normal appearing renal parenchyma. 
ference was not statistically significant $(\mathrm{p}=0.321)$. The mean \pm SD elasticity values of the lesions according to the histopathological type are shown in Table 1. The highest elasticity values were obtained from RCCs and the abscess. The elasticity values of TCCs and angiomyolipomas were similar.

Twenty percent of lesions in both groups were smaller than $3 \mathrm{~cm}$ in diameter. The median elasticity value was $21.82 \mathrm{kPa}$ (range: $8.48-97.26$ ) for lesions $<3 \mathrm{~cm}$, and $13.26 \mathrm{kPa}$ (range: $3.24-81.18$ ) for lesions $\geq 3 \mathrm{~cm}$ which did not reflect a significant difference $(\mathrm{p}=0.209)$.

Measurements of the renal cortex did not significantly differ between kidneys with malignant and benign lesions. The mean \pm SD elasticity values for adjacent renal cortex for groups 1 and 2 were $2.7 \pm 2.08$ and $2.75 \pm 1.35$, respectively.

SWER was detected for each lesion by dividing the highest stiffness value in the lesion by the highest value in the adjacent renal cortex. SWER did not significantly differ between the groups. However, there was a positive correlation between SWER and the highest SWE value of the masses for each group ( $\mathrm{p}=0.006, \mathrm{rs}=0.534$ for group 1 and $\mathrm{p}=0.018, \mathrm{rs}=0.6$ for group 2 ).

For group 1 a negative correlation was observed between the age of the patients and SWER value $(\mathrm{p}=0.047$, $\mathrm{rs}=-0.401)$. There was also a negative correlation between the SWER value and the SWE value of adjacent renal cortex $(\mathrm{p}=0.004, \mathrm{rs}=-0.555)$.

\section{Discussions}

US is generally used to detect renal solid tumors but is rarely the only method used to characterize solid renal masses. It is usually not possible to discriminate between benign and malignant tumors based on B-mode findings because of the overlapping US features [9,26,27].

SWE is a recently developed technique that provides quantitative measurements of tissue elasticity. The major advantages of SWE versus other US elastography techniques are that it provides true elasticity values of tissues (in $\mathrm{kPa}$ ) and does not need external compression. Thus, it is a more useful method for investigating the elasticity of visceral organs. Few studies have evaluated the elasticity of renal tumors [21-25]. To the best of our knowledge, there are only five such reports in the English language literature (two regarding strain elastography and three regarding ARFI elastography). Cut-off values for benign and malignant tumors have not yet been validated.

Onur et al [21] used strain elastography to assess solid renal tumors, and found that benign masses had a lower mean strain index values than malignant ones $(\mathrm{p}<0.0001)$; malignant tumors were 2.8 times stiffer than benign tu- mors. Elasticity significantly differs between normal and neoplastic tissues. One reason for the increased stiffness of lesions may be linked to increased cellularity due to increased mitosis. In our study, malignant renal tumors had slightly (but not significantly) higher ( 1.6 times higher) elasticity values than benign renal tumors. A possible reason for the different results across studies may be the different US devices used.

Onur et al [21] and Tan et al [22] compared elastography values of RCC and AML histotypes, and both reported a significant difference in elasticity between the two tumor types ( $<<0.0001$ and $p<0.001$, respectively). We obtained higher elasticity values for RCC than angiomyolipomas, consistent with previous research. RCCs were 1.8 times stiffer than angiomyolipomas.

In general, elasticity values of benign lesions are lower than malignant tissues and higher than normal tissues. However, there may be overlaps that need to be identified to improve the diagnostic performance of US elastography. Goya et al [25] found significant differences in elasticity between benign and malignant renal cortical tumors $(p=0.033)$. However, the SWE values of TCC were similar to those of benign cortical lesions. In our study, the mean elasticity values of TCCs were similar to those of AMLs. TCC is a challenging tumor when it involves the upper collecting system, and particularly when it is small. Histologically, TCC is a soft, fern-like tumor with loose connective tissue. These histological features may influence its mechanical properties. The RCCs and the abscess in our study also had similar elasticity values. Abscesses and inflammatory conditions in other parts of the body generally have lower elasticity values than normal tissues and malignant lesions. Our result might be due to the stage of the abscess. Before the liquefaction process, swelling and induration occur in the tissue, which may cause higher elasticity values. Thus, additional findings beyond an elastographic evaluation are needed for the diagnosis of an abscess.

SWER is another parameter for assessing the stiffness of tissue quantitatively in elastography. SWER has been used in breast [28] and prostate [29] imaging to differentiate malignant tumors from benign ones. Lu et al [23] used SWER values to discriminate between benign and malignant renal tumors in a large series that included 201 renal lesions (44 benign, 157 malignant). They found that mean SWER and SWE values of AML were significantly lower relative to RCC of any histotype: $1.92 \pm 0.85$ versus $2.27 \pm 0.85(\mathrm{p}=0.022)$ and $0.74 \pm 0.34$ versus $1.10 \pm 0.52$ $(p<0.001)$, respectively. We found that SWER values of RCCs were higher than those of AMLs (although the differences were not statistically significant), consistent with the results of $\mathrm{Lu}$ et al. We found a negative correla- 
tion between age and SWER for malignant tumors. This might be due to cortical elasticity decreasing with age. If renal parenchymal elastography values change with age, this might cause SWER to be a less valuable measure. Normative values for SWER relative to age may need to be determined. The utility of SWER versus SWE for discriminating between malignant and benign renal tumors needs to be investigated with a larger series.

The kidney differs from other visceral organs in structural and functional characteristics. The proximal and distal collecting tubules, vascular structures, calyces, and pelvis are major structures in its unique anatomy. This anatomical arrangement causes anisotropic delineation, making the kidney different from hepatic and prostatic tissue in SWE. Anisotropy is assumed to influence shear wave velocity, which may cause under- or overestimation of elastography values. Changes in vascularisation may reduce elasticity measurements of the kidney, or renal fibrosis secondary to chronic renal diseases may cause increased elasticity [30]. Further studies are required to establish normal and pathologic values of different anatomic regions of the kidney.

Our study had some limitations. First, we studied a limited patient population. In some lesion histotypes, the $n$ value was only 1 . Second, we did not take into consideration the subtypes of RCC or minimal fat angiomyolipoma. Elasticity changes between subtypes of RCC and fat-poor and fat-rich angiomyolipomas may be subjects for future studies. Third, the ROI size was constant, which could have impacted some of the parenchymal measurements. Newer technologies can overcome this, with the development of free hand ROIs. Finally, we did not assess inter- or intraobserver variability, but the method has been shown to be highly reproducible.

In conclusion, SWE is a noninvasive method that provides quantitative elasticity information on tissues. Overlaps among different types of renal lesions may be due to heterogeneity of the lesions, rather than the method itself. Larger study groups may clarify the other factors affecting SWE values under both normal and pathological conditions.

\section{Conflicts of interest: none}

\section{References}

1. Jemal A, Bray F, Center MM, Ferlay J, Ward E, Forman D. Global cancer statistics. CA Cancer J Clin 2011;61:69-90.

2. Silverman SG, Israel GM, Herts BR, Richie JP. Management of the incidental renal mass. Radiology 2008;249:16-31.

3. Stakhovskyi O, Yap SA, Leveridge M, Lawrentschuk N, Jewett MA. Small renal mass: what the urologist needs to know for treatment planning andassessment of treatment results. AJR Am J Roentgenol 2011;196:1267-1273.

4. Yip SK, Tan PH, Cheng WS, Li MK, Foo KT. Surgical management of angiomyolipoma: nephron-sparing surgery for symptomatic tumour. Scand J Urol Nephrol 2000;34:32-35.

5 . Woo S, Cho JY. Imaging findings of common benign renal tumors in the era of small renal masses: differential diagnosis from small renal cell carcinoma: current status and future perspectives. Korean J Radiol 2015;16:99-113.

6. Kutikov A, Fossett LK, Ramchandani P, et al. Incidence of benign pathologic findings at partial nephrectomy for solitary renalmass presumed to be renal cell carcinoma on preoperative imaging. Urology 2006;68:737-740.

7. Gurel S, Narra V, Elsayes KM, Siegel CL, Chen ZE, Brown JJ. Subtypes of renal cell carcinoma: MRI and pathological features. Diagn Interv Radiol 2013;19:304-311.

8. Barr RG., Peterson C, Hindi A. Evaluation of indeterminate renal masses with contrast-enhanced US: a diagnostic performance study. Radiology 2014;271:133-142.

9. Pallwein-Prettner L, Flöry D, Rotter CR, et al. Assessment and characterisation of common renal masses with $\mathrm{CT}$ and MRI. Insights Imaging 2011;2:543-556.

10. Cantisani V, Bertolotto M, Weskott HP, et al. Growing indications for CEUS: The kidney, testis, lymph nodes, thyroid, prostate, and small bowel. Eur J Radiol 2015;84:16751684.

11. Dyer R, DiSantis DJ, McClennan BL. Simplified imaging approach for evaluation of the solid renal mass in adults. Radiology 2008;247:331-343.

12. Fahey BJ, Nelson RC, Bradway DP, Hsu SJ, Dumont DM, Trahey GE.In vivo visualization of abdominal malignancies with acoustic radiation force elastography. Phys Med Biol 2008;53:279-293.

13. Arda K, Ciledag N, Aktas E, Aribas BK, Köse K. Quantitative assessment of normal soft-tissue elasticity using shear-waveultrasound elastography. AJR Am J Roentgenol 2011;197:532-536.

14. Thomas A, Degenhardt F, Farrokh A, Wojcinski S, Slowinski T, Fischer T. Significant differentiation of focal breast lesions: calculation of strain ratio in breast sonoelastography. Acad Radiol 2010;17:558-563.

15. Cantisani V, Grazhdani H, Ricci P, et al. Q-elastosonography of solid thyroid nodules: assessment of diagnostic efficacyand interobserver variability in a large patient cohort. Eur Radiol 2014;24:143-150.

16. Cantisani V, Lodise P, Di Rocco G, et al. Diagnostic accuracy and interobserver agreement of Quasistatic Ultrasound Elastography in the diagnosis of thyroid nodules. Ultraschall Med 2015;36:162-167.

17. Dietrich CF, Bamber J, Berzigotti A, et al. EFSUMB Guidelines and Recommendations on the Clinical Use of Liver Ultrasound Elastography, Update 2017 (Short Version). Ultraschall Med 2017;38:377-394.

18. Anvari A, Barr RG, Dhyani M, Samir AE. Clinical application of sonoelastography in thyroid, prostate, kidney, pancreas, and deep venous thrombosis. Abdom Imaging 2015;40:709-722. 
19. Waage JE, Rafaelsen SR, Borley NR, et al. Strain elastography evaluation of rectal tumors: inter- and intraobserver reproducibility. Ultraschall Med 2015;36:611-617.

20. Che D, Zhou X, Sun ML, Wang X, Jiang Z, Changjun-Wu. Differentiation of metastatic cervical lymph nodes with ultrasound elastography by virtual touch tissue imaging: preliminary study. J Ultrasound Med 2015;34:37-42.

21. Onur MR, Poyraz AK, Bozgeyik Z, Onur AR, Orhan I. Utility of semiquantitative strain elastography for differentiation betweenbenign and malignant solid renal masses. J Ultrasound Med 2015;34:639-647 .

22. Tan S, Özcan MF, Tezcan F, et al. Real-time elastography for distinguishing angiomyolipoma from renal cellcarcinoma: preliminary observations. AJR Am J Roentgenol 2013;200:W369-W375.

23. Lu Q, Wen JX, Huang BJ, Xue LY, Wang WP. Virtual Touch quantification using acoustic radiation force impulse (ARFI) technology for the evaluation of focal solid renal lesions: preliminary findings. Clin Radiol 2015;70:13761381.

24. Clevert DA, Stock K, Klein B, et al. Evaluation of Acoustic Radiation Force Impulse (ARFI) imaging and contrastenhanced ultrasound in renal tumors of unknown etiology in comparison to histological findings. Clin Hemorheol Microcirc 2009;43:95-107.

25. Göya C, Daggulli M, Hamidi C, et al. The role of quantitative measurement by acoustic radiation force impulse imaging in differentiating benign renal lesions from malignant renal tumours. Radiol Med 2015;120:296-303.

26. Vikram R, Ng CS, Tamboli P, et al. Papillary renal cell carcinoma: radiologic-pathologic correlation and spectrum of disease. Radiographics 2009;29:741-754.

27. Jinzaki M, Silverman SG, Akita H, Nagashima Y, Mikami S, Oya M. Renal angiomyolipoma: a radiological classification and update on recent developments in diagnosis and management. Abdom Imaging 2014;39:588-604.

28. Çebi Olgun D, Korkmazer B, Kılıç F, et al. Use of shear wave elastography to differentiate benign and malignant breast lesions. Diagn Interv Radiol 2014;20:239-244.

29. Correas JM, Drakonakis E, Isidori AM, et al. Update on ultrasound elastography: miscellanea. Prostate, testicle, musculo-skeletal. Eur J Radiol 2013;82:1904-1912.

30. Peride I, Rădulescu D, Niculae A, Ene V, Bratu OG, Checheriță IA. Value of ultrasound elastography in the diagnosis of native kidney fibrosis. Med Ultrason 2016;18:362369. 